\title{
GENDER DIFFERENCES IN HIGHER EDUCATION DEGREE CHOICE
}

\author{
Cristina Mesquita ${ }^{1,2}$, Rui Pedro Lopes ${ }^{1,3}$ \\ ${ }^{1}$ Instituto Politécnico de Bragança (PORTUGAL) \\ ${ }^{2}$ Research Center in Basic Education, Instituto Politécnico de Bragança (PORTUGAL) \\ ${ }^{3}$ Research Center in Digitalization and Industrial Robotics, Instituto Politécnico de Bragança
}

(PORTUGAL)

\begin{abstract}
Choosing and enrolling in a higher education degree and, consequently, selecting a profession, is still conditioned by social and cultural factors characterized by gender stereotypes that continue to attract more men to technical and technological careers and more women to teacher training and social work. However, the nature of gender inequities changed over the recent decades, becoming more complex. This complexity can be observed in the men and women's career preferences. Even considering that vocation influences the choices, the stability that some careers represent, regarding the immediate access to employment and to reasonable salaries also influences the options made by men and women. Besides that, literature has been highlighting that both the students' self-perception and the perceptions about degrees and social encouragement also influences their choices.
\end{abstract}

This study analyses the perception that higher education students have about themselves and the degrees they have enrolled. More specifically, it analyses the gender stereotypes that persist within themselves and their perception about the assumed affinity between gender and areas and professions.

The study follows a quantitative methodology approach, using a questionnaire for data collection. The questionnaire was structured based on reference literature about gender stereotypes, gender differentiation in higher education and the values about professions. Students from 6 degrees in different areas participated in the study (social work, nursing, teacher training, engineering informatics and mechanics and sports). Data were interpreted through a multivariate analysis with the independent variable gender and degree, to assess the differences in the questionnaire responses.

There seems to exist an image of man and woman associated with some degrees and professions. Although all of the students assume a complete freedom of choice for enrolling higher education degrees, the options seem to be determined by social and gender stereotypes and also by professional stability.

Keywords: higher education, profession selection, gender stereotypes.

\section{GENDER DIFFERENCES AND CAREER CHOICE}

Equality between women and men has been assumed in the international political agenda. The European Union Treaties establish this principle since 1957, that has been reinforce with several lows and with specific strategies and programs [1].

A multiple dimensions perspective on the women's status reflect the considerable progresses that have been happening in the last century, reflecting the benefits brought by education that significantly increases the women's presence in the labour market and in the social and political spheres. This evolution has been strengthened with other initiatives, reinforcing the employment equality, salary transparency, access to higher levels of education, fight against gender violence, and, more recently, opportunities to access and succeed in male-dominated professions.

The statistics described in several reports confirm this reality. The 2017 Report on equity between women and men in the EU points out that employment rates for men and women have improved, but the gap in the working age is stabilizing (mainly due to the increase in the retirement age) [2]. The same report stresses that women work more hours in non-formal environments than men, revealing that they continue to assume more parental and family responsibilities. In addition, the study also reveals that there are differences between the wage levels of women and men for equal work. These differences are more pronounced in higher-salary professions. 
It should be noted that women and men have different career options, with more women in professions related to social action, education and social sciences and more men in professions related to engineering. The public sector is a major employer of women, such as teacher and nurses, which can be a factor for the wages gap between gender.

Considering this reality, the need to better understand the career choice of students and how these options relate to the experiences they have in schools arises.

The results of PISA 2015 [3], which highlights the performance of 15-year-old students in science, reveal that this is the area of studies where differences between boys and girls are less pronounced. Even though gender differences in science performance tend to be small, on average, in 33 countries and economies, the share of top performers in science is larger among boys than among girls. Finland is the exception, in which girls are more likely to be top performers than boys.

This fact is also observed in mathematics. Finland is still the only country where girls perform better than boys, but also on the fourth grade. On the opposite, a significant gap in favour of 15-years old boys can be observed in Belgium, Denmark, Germany, Ireland, Croatia, Italy, Austria, Poland, Portugal, Spain and the UK.

In all countries, girls achieve a much higher level of proficiency in reading than boys, although the gender gap has been decreasing since 2009: boys' performance improved, while girls' performance deteriorated.

According to Eurostat, in 2015 women were representing $54,1 \%$ of all higher education students in the EU-28. This percentage was slightly higher in the master degree $(57,1 \%)$ and a little lower in the bachelor degree $(53,2 \%)$ and in the short duration programmes $(52,1 \%)$. However, the majority of $\mathrm{PhD}$ students are men $(52,2 \%)$. Almost a third $(32,2 \%)$ of all the higher education students were enrolled in social sciences, journalism, information, management, administration or law. There were more women than men in these programmes $(57,6 \%)$. The second most common study area was engineering, industry and construction, representing $15,8 \%$ of all students in higher education. In this area, $74 \%$ of the students were men. Health and social studies represented a percentage of $13,1 \%$ of all students, of which $71,9 \%$ were women. Also, education had $77,8 \%$ of women.

Overall, women represented almost two thirds of all the students in the arts and humanities area $(64,6 \%)$, and men almost two thirds of the students in natural sciences, math, statistics and ICT $(61,3 \%)[4]$.

This differences between science, maths and humanities reveal that there is an impact on career expectations between genders, even among students of similar performances in science and who reported the same level of enjoyment of science. Across OECD countries, $25 \%$ of boys and $24 \%$ of girls reported that they expect to work in a science-related occupation. However, sciences have a different interpretation among them. Girls seek working as health professionals more than boys, which see themselves as becoming information and communications technologies (ICT) professionals or engineers.

Google conducted a study to identify and understand the factors that influence women's decisions behind their choice of Computer Sciences career [5]. The study highlights the following factors:

- Social encouragement: characterized by positive reinforcement of family and peers.

- Self-perception: by their good performance in mathematics and by their interest in challenges and problem solving, as an asset in a successful career.;

- Academic exposure: previous experiences with the area of computer science;

- Career perception: the familiarity with the area and the realization that this is a career with social impact.

The study also underlines that uncontrollable factors, such as having a family member in a Computer Science related field, having a family member with a Computer Science degree, and geography, were statistically insignificant. Factors such as early exposure to technology, age of first computer exposure, access to mobile devices, natural aptitude, and topical depth/breadth of existing pre-college and Computer Science curriculum also do not contribute to the choice of Computer Science related careers. 
Considering this scenario, the present study seeks to analyse students' self-perception and their perception of careers and professions, in order to understand what led them to choose the courses they attend.

\section{METHODOLOGY}

The choice of the degree is closely tied to the profession students want to pursuit. There is a social perception, confirmed by several studies and statistics, that men and women have different career choices, in average, with the arts and humanities more female-dominated professions and engineering more male-dominated professions. The work described in this paper intends to study the opinion students' have of themselves and their perception on the degree and career choice. The study was performed with students of the $1^{\text {st }}, 2^{\text {nd }}, 3^{\text {rd }}$ years of the degrees in Sports, Basic Education, Social Work, Informatics Engineering and Mechanical Engineering, and of the $1^{\text {st }}, 2^{\text {nd }}, 3^{\text {rd }}$ and $4^{\text {th }}$ years of the degree in Nursing.

Data was collected with a closed-questions questionnaire, structured in three sections. The first section was used to characterize the respondents in terms of gender, degree and age. Section 2 required the students scale their answers in 7 levels of agreement with a set of statements about gender representations on degree choices. These statements were carefully designed to contain both stereotyped and non-stereotyped terms, to assess how students react to this difference. The last section also contained statements about the students' self-perception and the perception on the degrees that the students had to scale in 7 levels of agreement.

As an example, the stereotyped questions used explicit comparison between genders, such as:

- Women have more predisposition for professions that imply taking care of other people, or

- Men assume positions of leadership better than women.

Non-stereotyped questions used words that did not induce explicit differentiation between gender:

- The choice of the degree depends more on de sensitivity of the individual than the gender, or

- Men and women have equal skills for both mathematics and problem solving.

A total of 306 answers were received and considered valid, with 25 from Sports (8,2\%), 52 from Basic Education (17\%), 70 from Social Work $(23,2 \%), 70$ from Nursing $(23,2 \%), 84$ from Informatics Engineering (27,5\%) and 4 from Mechanical Engineering (1,3\%) (Figure 1).

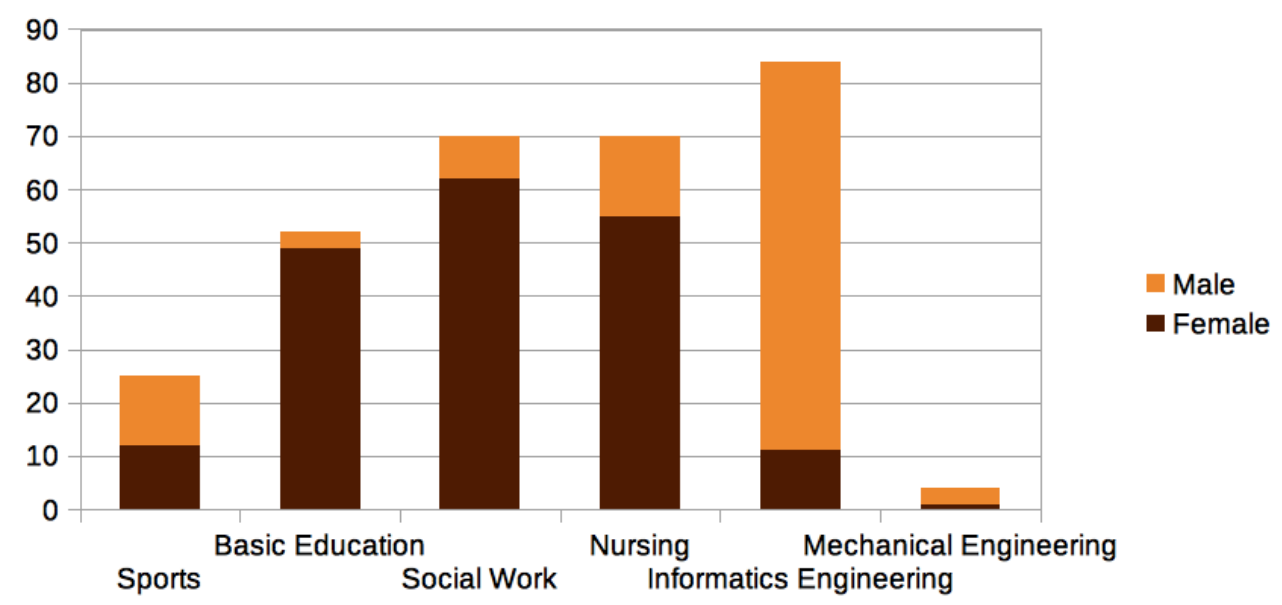

Figure 1. Characterization of the respondents by degree and gender.

The percentage of respondents per curricular year was higher in $1^{\text {st }}$ year students $(33 \%)$, followed by $3^{\text {rd }}$ year $(31,7 \%), 2^{\text {nd }}$ year $(27,1 \%)$ and, finally, $4^{\text {th }}$ year students, which only happens in one degree $(8,2 \%)$.

In total, there are more female respondents $(62,1 \%)$ than male respondents $(37,9 \%)$, justified by the gender distribution differences between degrees (Figure 2). 


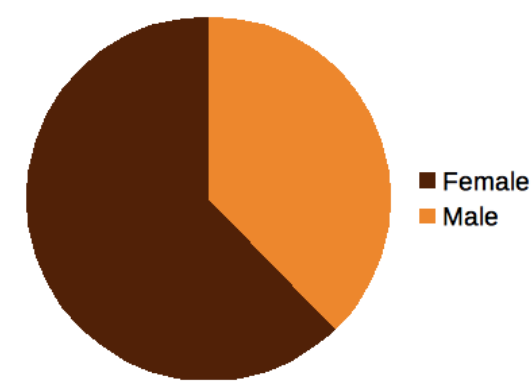

Figure 2. Characterization by gender.

\section{RESULTS}

The initial step was to analyze the data related to the gender representations for choosing the degree. In this part of que questionnaire, statements were grouped by stereotyped and non-stereotyped and sorted by level of agreement by gender. The analysis was performed with the software $R$ and visualized according to their degree of agreement.

\subsection{Stereotyped and Non-stereotyped questions}

As mentioned before, each statement was scaled between 1 and 7 . By selecting 7 , the student was in complete agreement with the statement and with 1 with complete disagreement. The non-stereotyped (neutral) statements were the following:

- Any higher education degree is appropriate both for women and for men (appropriate).

- Both men and women are competent in any area (competent).

- Both men and women can make efficient decisions in any professional area (decisions).

- The choice of the degree depends more on the sensitivity of each on than of the gender (sensitivity).

- Both women and men have the same capacities for math and problem resolution (same_capacity).

When confronted with these neutral statements, which place both women and men in an equal position in relation to the possibilities and competences for the career choice, students do not seem to make any distinction (Figure 3). Moreover, almost everyone has a strong agreement with all the statements, with a slight difference in relation with the use of reason vs. intuition. They all agree that any gender can be competent professionals in any area and manifest that both men and women can make efficient decisions as well. These perceptions probably arise from the fact that students have contact with both genders in the degree and are able to recognize the possibilities of both in this educational context, allowing the construction of a positive action for both men and women in the profession.

In relation to the stereotyped questions, these included the following:

- Women have more predisposition for professions that imply taking care of other people (care).

- Men deal better with professions that require using machines (machines).

- Men assume leadership positions better than women (lidership).

- Women have a natural predisposition for professions in the area of social and sciences and humanities (social_sciences).

- Men have a natural predisposition for professions in the area of engineering and other technical areas (technical_areas).

- In work, men use more the reason and women use more intuition (intuition)

- Gender influences the choice of the degree, because there are degrees more adequate for women and others more adequate for men (influence).

- The professions in the social sciences and humanities demand more patience, so men don't choose them as much (patience). 
- Women reveal good management capacity (management).

- Working in teams is easier with women (team).

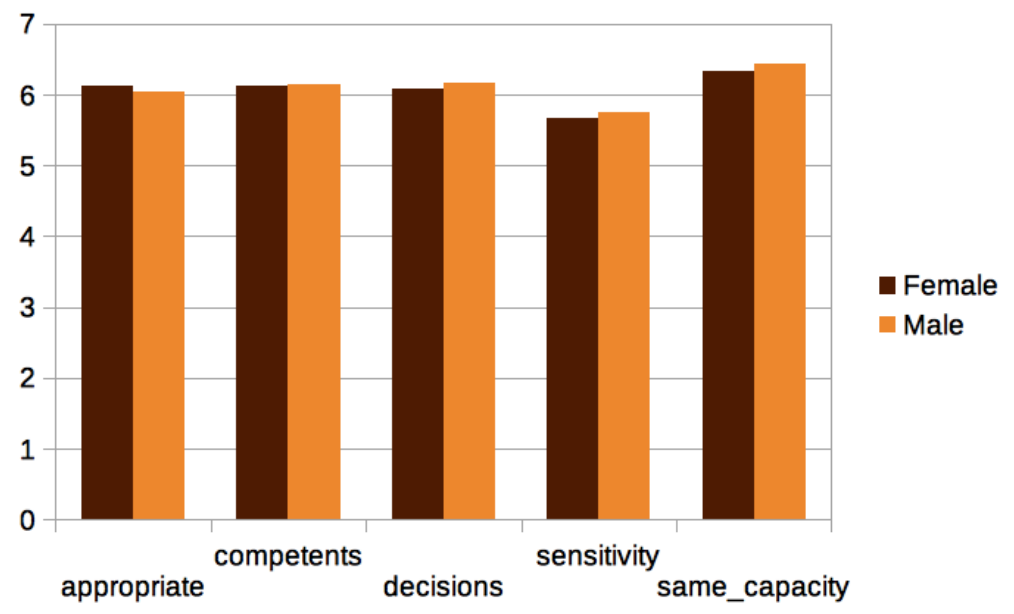

Figure 3. Results in the neutral (non-stereotyped) statements.

Based on these set of questions that transmit gender stereotypes, we can see that the differences of opinion between men and women are more remarkable than in the previous case (Figure 4). Moreover, the level of agreement with the statements is lower, with women demonstrating a higher level of disagreement than men. The exception is the good management capacity, in which women consider that they have more capacity than men.

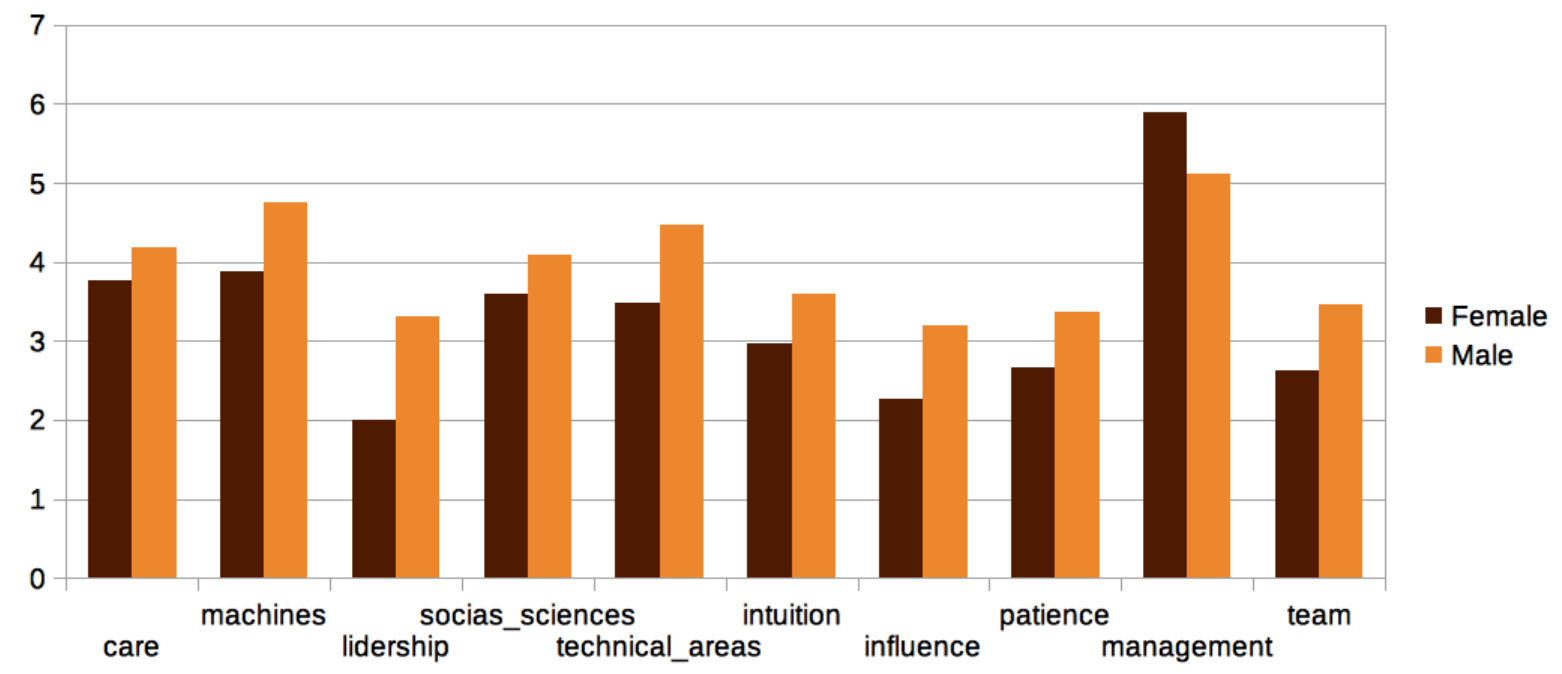

Figure 4. Stereotyped statements.

The third part of the questionnaire was related to the perceptions that students have about themselves and about the career. It is composed of 20 statements in a Likert scale, to classify their level of agreement (from 1 to 7 ). The results were compiled in the following sections.

\subsection{Self-perceptions and perceptions about the career}

The 20 statements were grouped in 17 indicators. The students' answers were calculated and sorted according to the agreement level. The initial analysis was related to the valued characteristics by gender, overall (Figure 5). 


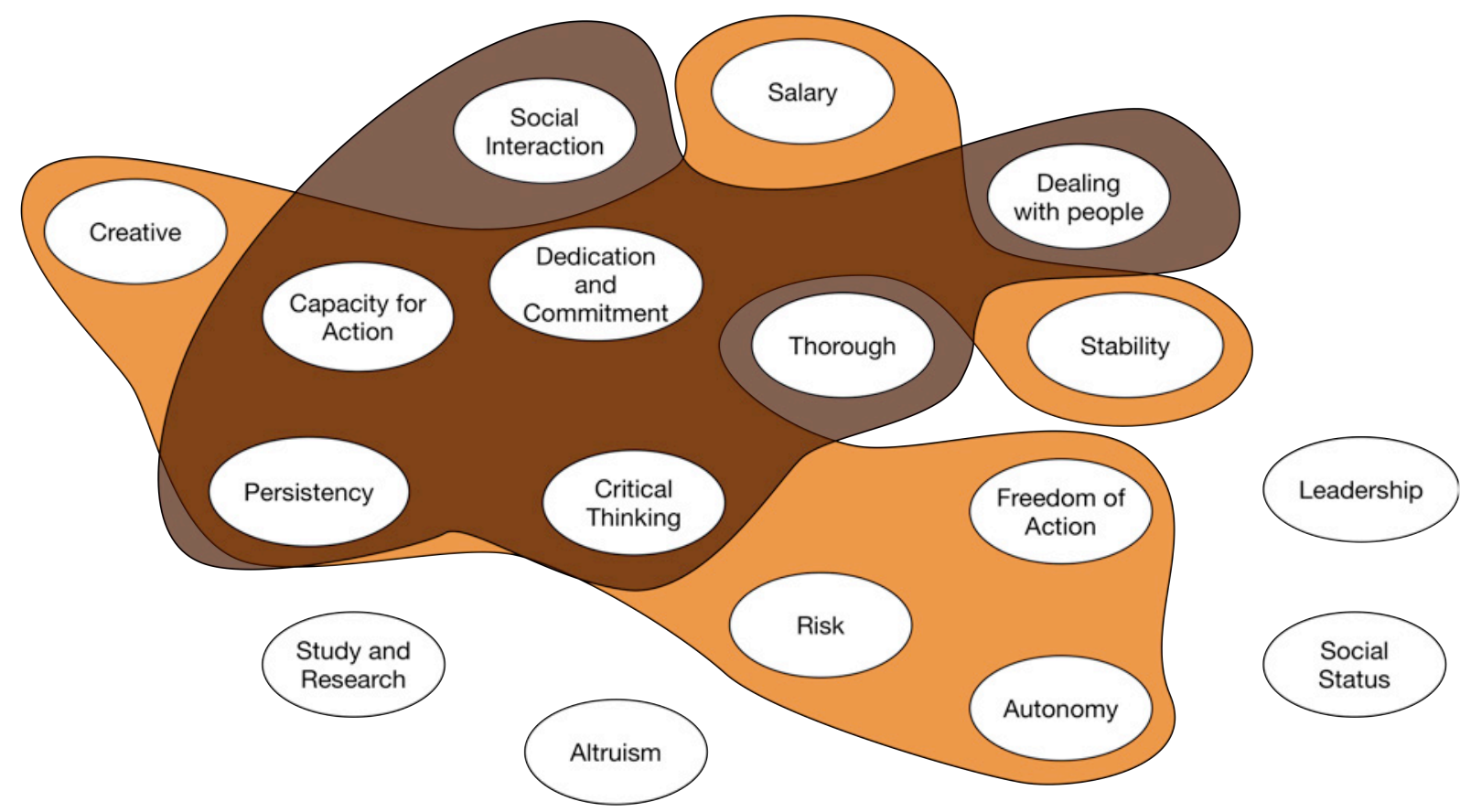

Figure 5. Overall valued characteristics by gender.

Both women and men value common characteristics, represented by an overlap in Figure 5, namely, the Persistency, Capacity for Action, Dedication and Commitment, and Critical Thinking, in all professions and all areas. However, women attribute more importance to the social interaction, being thorough and dealing with people, and men value more the creativity, risk taking, autonomy, freedom of action, stability and salary instead.

\subsection{Differences between gender in women-dominated and men-dominated professions}

As confirmed in section 2 (Figure 1), there are degrees dominated by female students, such as Social Work, and others dominated by men, such as Informatics Engineering. The analysis was performed on the self-perceptions and the perceptions on the degree by women in the first and men in the second (Figure 6).

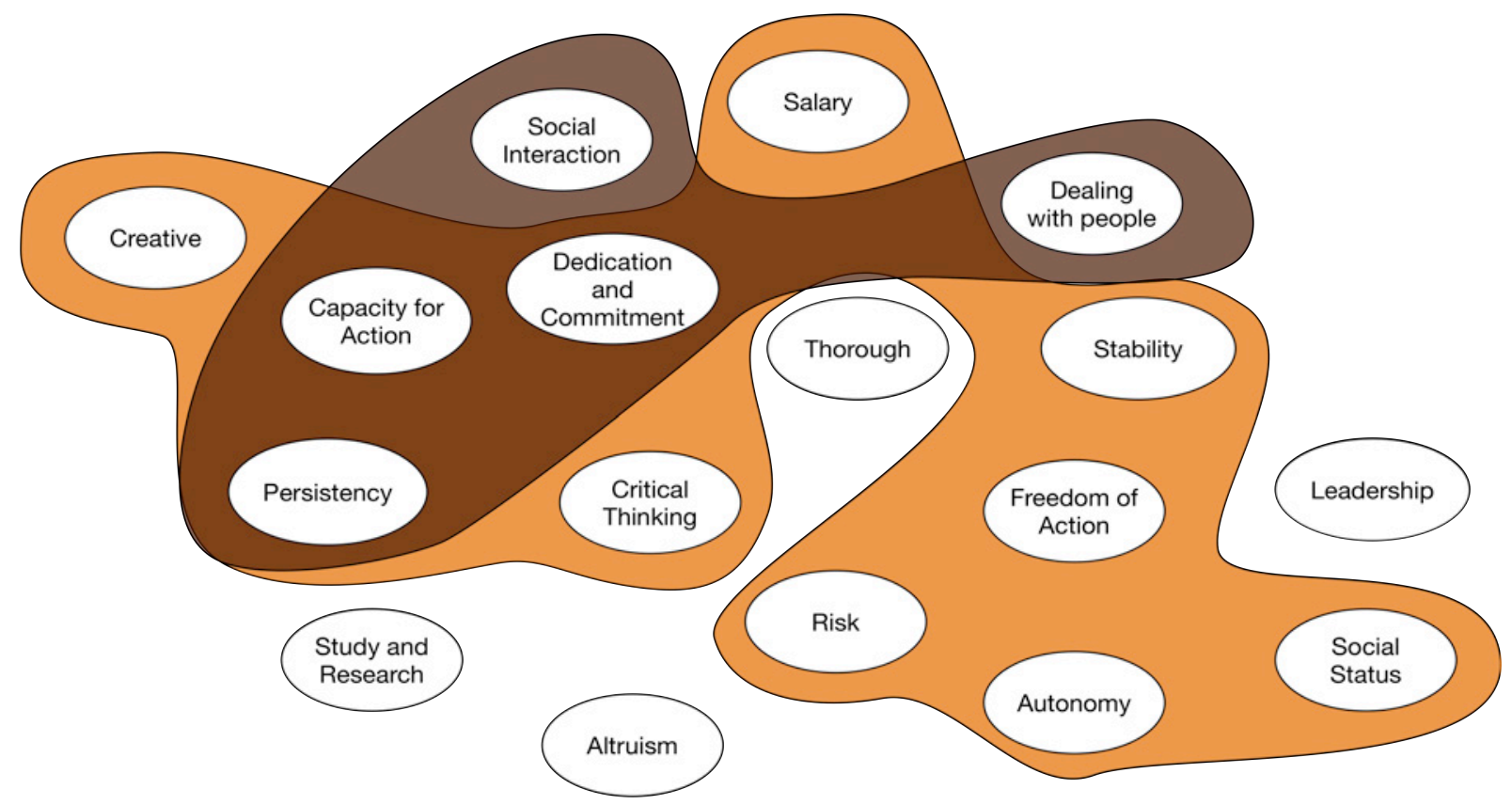

Figure 6. Differences between gender in women-dominated and men-dominated degrees. 
Both genders value more the Persistency, Capacity for Action, and Dedication and Commitment, recognizing that these characteristics are fundamental for both social work, by women, and ICT by men. However, women of social work value more the Social Interaction and Dealing with People, as expected from the professional profile of this degree. In Informatics Engineering, men value the Salary, Creativity, Critical Thinking, Stability, Freedom of Action, Risk, Autonomy and Social Status. This perception is related to the area of the profession and it is not clear if gender is an influencing factor. However, the reasons women choose more Social Work and men choose more Informatics Engineering may be related to the self-perception they have and the satisfaction they expect to get from the professional career.

\subsection{Differences between gender in Nursing}

In the degree of Nursing, the analysis was made in both the most valued (Figure 7) and in the least valued (Figure 8) characteristics, for both men and women.

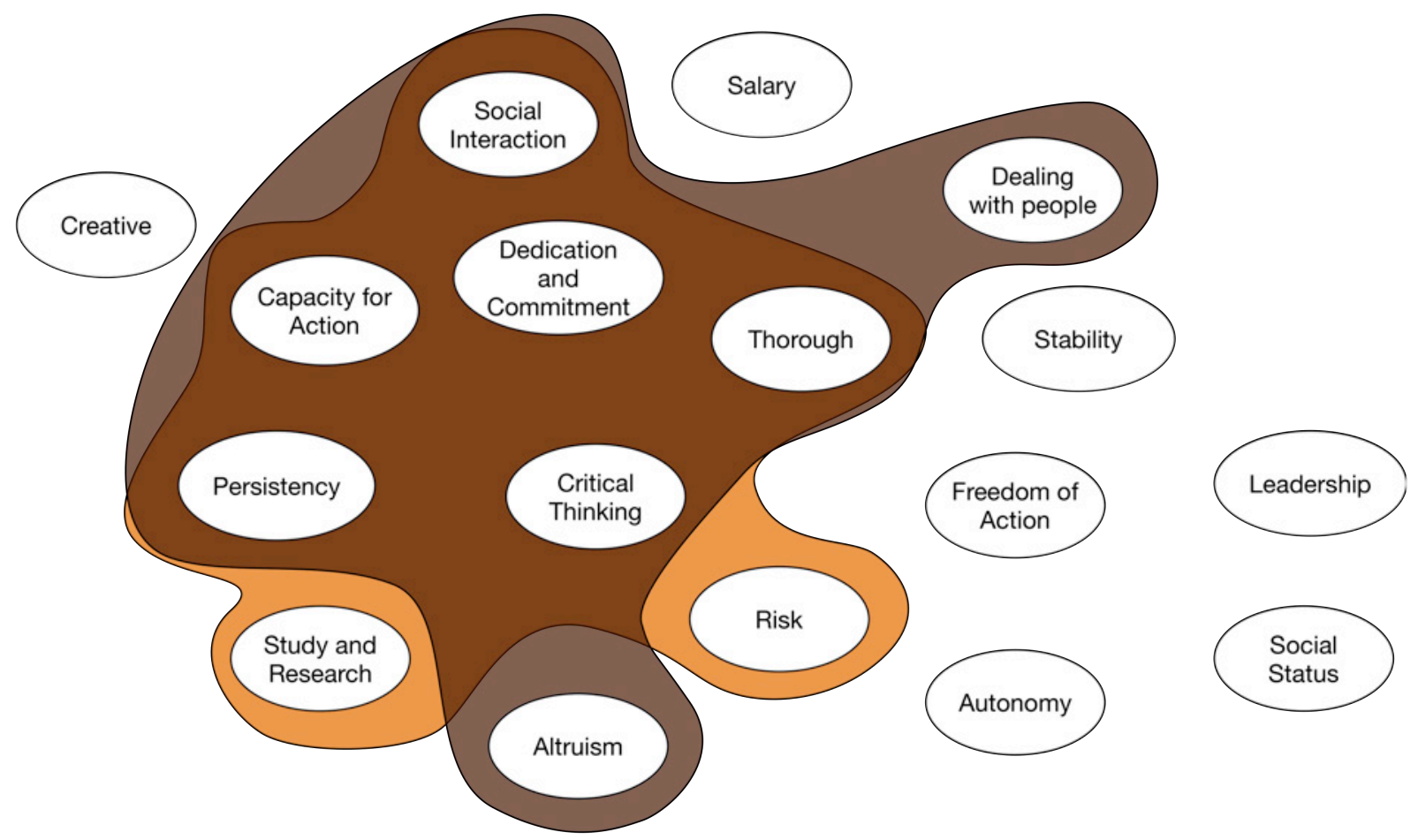

Figure 7. Nursing: the most valued characteristics between male and female students.

The Persistency, Critical Thinking, Capacity of Action, Dedication and Commitment and being Thorough has been identified by both men and women as important characteristics for the development of the nursing career. However, women relate the profession with the importance of the others' welfare (Altruism) and recognize that it is important to Deal with People. Men, surprisingly, see the career as an opportunity to continue Studying and Researching and they appreciate the challenge inherent to the activity (Risk).

On the other hand, to further assess the perception of the Nursing students, an analysis of the least valued characteristics was also made (Figure 8). Nor the Salary nor the Leadership is valued by both women and men. The latter also consider Altruism and Creativity to not be important in the development of the career. In fact, Nursing is a very practical degree, and students are learning technics and procedures to help them dealing with the patients. In this sense, it is possible that students do not give much importance to Altruism and Creativity. 


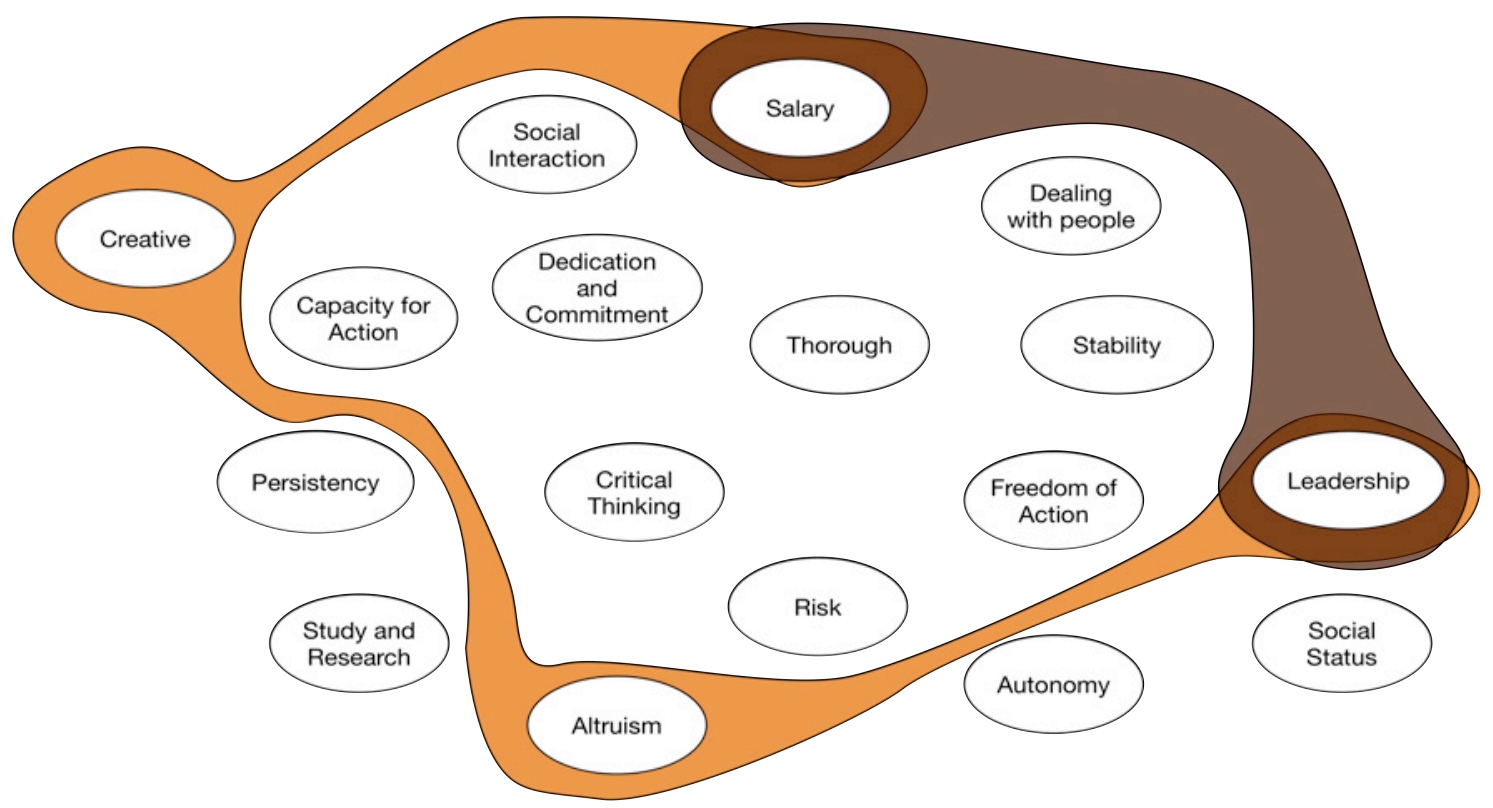

Figure 8. Nursing: the least valued characteristics between male and female students.

There seems to be insignificant differences between men and women that choose Nursing as a career. This may reveal that the male respondents have a self-perception and a perception of the career close to the women's perception.

\section{CONCLUSIONS}

There is a social perception that men and women both choose different degrees and have different career choices. The reasons for this are not clear, although they may arise from gender stereotypes and/or self-perception of their characteristics.

This study confirms that there are still women-dominated professions, such as Nursing, Social Work and Basic Education, and men-dominated professions, such as Informatics and Mechanical Engineering. Women-dominated professions is a social and historical construct. This means that women had the right to assume professions that seemed an extension of the home activity. Men, on the other hand, have selected technical professions, driven by tools and risk-taking activities.

When facing a neutral statement, both women and men feel a sense of equality between gender and profession. However, when the statement has a stereotype, the definition of equality is less visible, and both women and men seem to have stereotyped perceptions.

The self-perception and the perception of the professions seems to be influencing factors of their choice, also confirmed by the Google study [5]. However, it is necessary to understand all the factors that influence the students' choices. This is better achieved through a qualitative analysis, with selected and representative students of each degree.

For the future, it is important to study the reasons that motivate women who choose men-dominated professions and men who choose women-dominated professions.

\section{REFERENCES}

[1] M. Schonard, 'Equality between men and women', European Union, Brussels, Belgium, 2018.

[2] EU, '2017 Report on equality between women and men in the EU', European Union, Brussels, Belgium, 2017.

[3] OECD, PISA 2015 Results (Volume I). OECD Publishing, 2016.

[4] Eurostat, 'Tertiary education statistics', Eurostat, 2017.

[5] Google, 'Women Who Choose CS - What Really Matters', Google, Mountain View, CA, USA, 2014. 